\title{
Síntese da parede abdominal. Avaliação de dois tipos de sutura contínua em ratos $^{1}$
}

\author{
Vanessa Medeiros Loureiro ${ }^{2}$ \\ Djalma José Fagundes ${ }^{3}$ \\ Murched OmarTaha ${ }^{4}$
}

\begin{abstract}
Loureiro VM, Fagundes DJ, Taha MO. Síntese da parede abdominal: avaliação de dois tipos de sutura contínua em ratos. Acta Cir Bras [serial online] 2003 Maio-Jun;18(3). Disponível em URL: http://www.scielo.br/acb.
\end{abstract}

RESUMO - Objetivo: Comparar a sutura simples contínua e a sutura contínua em oito vertical no fechamento da parede abdominal de ratos. Métodos: Quarenta e oito ratos machos Wistar, foram submetidos a laparotomia padronizada e fechamento da parede abdominal com sutura simples contínua $(n=24)$ e sutura contínua em oito-vertical $(n=24)$, com fio de polipropileno. No $7^{\circ}$ e $14^{\circ}$ pós-operatório foram submetidos a eutanásia 12 animais de cada grupo e deles retirados a camada músculo-aponevrótica da parede abdominal envolvendo a cicatriz operatória e preparados para exames histológico e imunohistoquímico. Os segmentos levados ao exame histológico foram corados por Hematoxilina-eosina sendo feita observação qualitativa do processo cicatricial e Picrosirius red F3BA, para avaliação quantitativa do colágeno. Também foram estudadas as porcentagens de macrófagos na linha de sutura por imunohistoquímica. Para a quantificação de macrófagos e fibras colágenas foi utilizado avaliação histológica por digitalização de imagem, baseados nos princípios de espectrofotometria. Os dados encontrados foram analisados estatisticamente pelos testes quiquadrado, exato de Fisher e Mann-Whitney $(\mathrm{p} \leq 0,05)$. Resultados: A análise qualitativa, nos parâmetros necrose, fibrose, neovascularização, presença de abscesso, reação de corpo estranho e coaptação das bordas de sutura, não mostrou dados significantes nos dois grupos aos 7 ou 14 dias. A porcentagem de fibras colágenas foi significantemente maior, apenas no $7^{\circ}$ dia, na sutura contínua em oito-vertical. A porcentagem de macrófagos mostrou-se significantemente maior na sutura simples contínua no $7^{\circ}$. dia. Conclusão: No $7^{\circ}$ dia de pós-operatório a parede abdominal suturada em oito vertical apresenta significantemente, maior quantidade de fibras colágenas e menor quantidade de macrófagos do que a suturada por técnica contínua. Aos 14 dias de observação as suturas mostraram-se morfologicamente semelhantes.

DESCRITORES - Abdome. Ratos Wistar. Técnicas de sutura. Parede abdominal.

\section{Introdução}

A abundância de literatura cirúrgica a respeito das técnicas operatórias para fechamento da parede abdominal, traduz, de certo modo, a falta de consenso sobre uma técnica de sutura ideal ${ }^{1,2,3,4,5}$.

Uma pesquisa recente de meta-análise com estudos randomizados, concluiu que os melhores resultados

1. Resumo de Tese de Mestrado apresentada no Programa de Pós-Graduação em Técnica Operatória e Cirurgia Experimental da Universidade Federal de São Paulo - Escola Paulista de Medicina (UNIFESP-EPM).

2. Mestre em Técnica Operatória e Cirurgia Experimental pela UNIFESP-EPM.

3. Professor Adjunto do Depto. de Cirurgia da UNIFESP-EPM e Coordenador do Programa de Pós-Graduação em Técnica Operatória e Cirurgia Experimental da Universidade Federal de São Paulo-Escola Paulista de Medicina (UNIFESP-EPM).

4. Professor Visitante da Disciplina de Técnica Operatória e Cirurgia Experimental da Universidade Federal de São Paulo-Escola Paulista de Medicina (UNIFESP-EPM). 
ocorreram usando a técnica de fechamento abdominal com sutura contínua, "em massa" (incluindo todos os planos anatômicos de uma só vez), com fio monofilamentar absorvível ${ }^{6}$.

Uma revisão da literatura médica em língua inglesa $^{7}$, sobre as perspectivas de técnicas usuais, novíssimas técnicas e recomendações sobre o fechamento da parede abdominal, concluiu que a sutura contínua deve ser realizada mantendo uma razão de 5:1 ou 4:1 entre o comprimento do fio e o comprimento da ferida operatória. Este seria o fator fundamental para evitar tensão e isquemia na linha de cicatrização e assim prevenir as deiscências e/ou hérnias ${ }^{8}$.

A sutura contínua é também considerada segura e confiável mesmo quando em situações de risco como nas operações de urgências, nas infecções em cirurgia, e outras situações patológicas como anemia, obesidade, diabetes e hipoproteinemia ${ }^{9}$. Nas situações em ocorrem aumento da pressão intra-abdominal também se beneficiam da sutura contínua ${ }^{10}$.

Jones et al. ${ }^{11}$ propuseram o fechamento em plano único da parede abdominal em humanos, onde se incluía o plano músculo-aponeurótico e o peritônio, com pontos separados em "figura de oito vertical", com fio de aço. Observaram vantagens no que tange ao menor índice de infecções e deiscências.

Meeks et al. ${ }^{12}$, em um estudo experimental em ratos, modificaram a sutura com fio absorvível em pontos separados, tipo "figura de oito vertical", para uma sutura contínua, comparando-a com sutura contínua em plano único. A proposta apoiou-se em dados racionais sobre o estudo de polias, demonstráveis matematicamente, no qual a disposição espacial deste tipo de sutura, diminuiria a tensão na linha de sutura e manteria a proporção de comprimento ferida/fio em 4:1. O estudo experimental confirmou a vantagem da proposição sobre a sutura contínua convencional.

Não se obteve, na revisão da literatura, outras informações sobre a técnica proposta. Contudo considerando o racional da mesma e as idéias mais recentes da literatura sobre a sutura contínua, pareceu pertinente uma investigação sobre as possibilidades da mesma.

O objetivo desta pesquisa, em animal de experimentação, foi verificar a adequação desta proposição de técnica operatória, usando um tipo de fio inabsorvível e estabelecendo novos critérios de avaliação dos resultados do ponto de vista macroscópico, histológico e imunohistoquímico.

\section{Métodos}

\section{Amostra}

Ratos machos ( $\mathrm{n}=48)$, da linhagem Wistar-Adolfo Lutz-UFMC, com peso variando entre 310 a 353 gramas, adultos, procedentes do Biotério da Universidade Federal de Mato Grosso do Sul (UFMS), foram distribuídos aleatoriamente em dois grupos.

Os animais do Grupo I ( $\mathrm{n}=24)$ foram submetidos à sutura contínua da parede abdominal, em plano único, tipo chuleio simples transverso, incluindo o peritônio, músculo reto abdominal e a sua aponeurose , com fio de polipropileno $4-0^{(2)}$.

Os animais do Grupo II $(n=24)$ foram submetidos à sutura contínua da parede abdominal, em plano único, tipo oito vertical preconizada por Jones et al. ${ }^{(11)}$ e modificada por Meeks et al. ${ }^{(12)}$, com fio de polipropileno 4-0.

Os animais de cada grupo foram redistribuídos em dois subgrupos de 12 ratos conforme a data de avaliação aos 7 e 14 dias, sendo chamados Grupo I - 7 (sutura contínua com avaliação em 7 dias); Grupo I14 (sutura contínua com avaliação em 14 dias); Grupo II- 7 (sutura em oito vertical com avaliação em 7 dias); Grupo II-14 (sutura em oito vertical com avaliação em 14 dias).

\section{Procedimentos}

Os animais foram anestesiados com tiopental sódico por via intraperitoneal, na dose de $50 \mathrm{mg} \cdot \mathrm{Kg}^{-1}$, permanecendo em respiração espontânea. Procedeuse à incisão xifo-púbiana , com deslocamento lateral da pele, expondo a linha alba.

Os locais em que seriam aplicados os pontos para síntese, em ambos os grupos, foram marcados com corante azul de metileno, no total de cinco pontos com comprimento total de $40 \mathrm{~mm}, 10 \mathrm{~mm}$ de distância entre eles, $5 \mathrm{~mm}$ equiidistante da linha alba .

Foi realizada a incisão mediana, sobre a linha alba, de $4 \mathrm{~cm}$ de extensão.

A síntese do plano peritônio-músculo-aponeurótico procedeu-se:

A) Grupo I - sutura contínua em plano único, tipo chuleio simples transverso, utilizando fio de polipropileno azul 4-0, monofilamentado, não absorvível, com agulha atraumática, cilíndrica com circunferência de 2,5 centímetros, passando-se o fio nos pontos anteriormente demarcados com azul de metileno (Figura 1). 


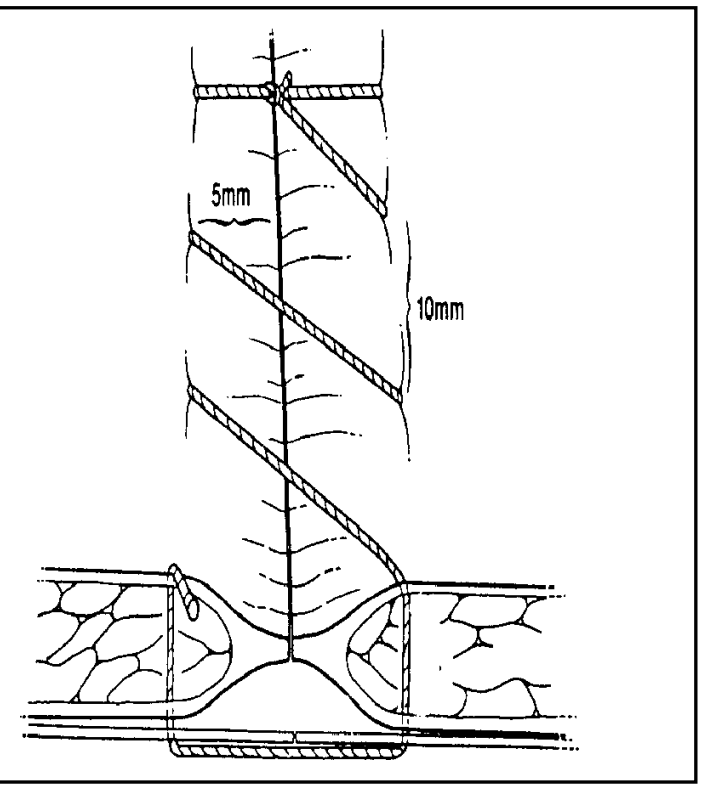

FIGURA 1 - Desenho esquemático da sutura simples contínua Grupo I (modificado de Meeks et al. ${ }^{12}$ ).

B) Grupo II - sutura contínua em oito vertical (longe-perto, perto-longe), com o mesmo material da sutura do Grupo I nos locais anteriormente demarcados (Figura 2).

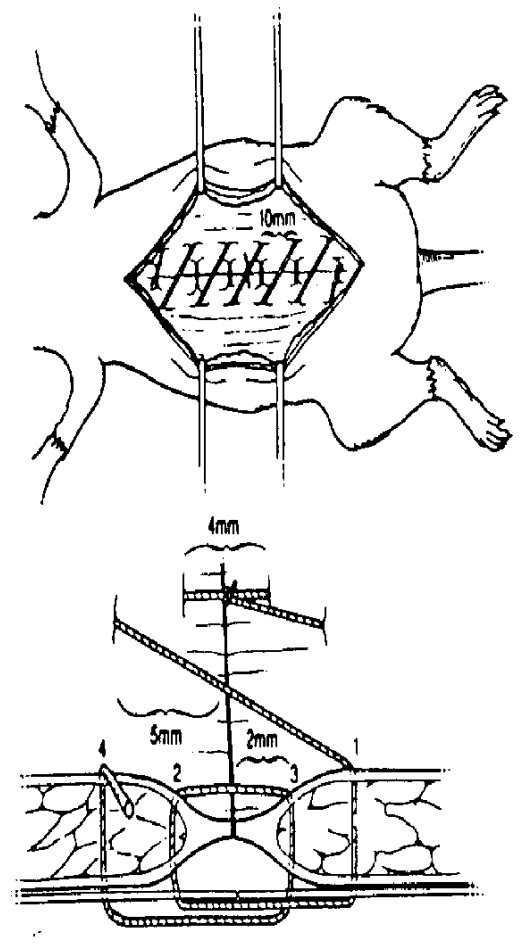

FIGURA 2 - Desenho esquemático da sutura continua em oitovertical [longe-perto, perto-longe) - Grupo II (modificado de Meeks et al. ${ }^{12}$ ).
Em ambas as suturas o primeiro ponto cefálico e o último caudal foram amarrados com um primeiro nó duplo, seguido de mais três nós simples ${ }^{(4)}$.

Após observação por um período de sete ou quatorze dias os animais foram identificados, pesados e anestesiados com procedimento idêntico ao da primeira operação.

Cada rato foi imobilizado na mesa operatória, efetuando-se a abertura da cicatriz cutânea expondose o plano músculo-aponeurótico e a linha de sutura anteriormente realizada. A parede abdominal foi retirada em bloco, incluindo-se $3 \mathrm{~cm}$ de comprimento da linha de sutura e preparada para estudo histológico e imunohistoquímico.

A análise histológica das lâminas coradas pela hematoxilina-eosina fez a avaliação qualitativa, dos parâmetros necrose, fibrose, neovascularização, presença de abscesso, reação de corpo estranho e coaptação das bordas de sutura,nos dois grupos aos 7 ou 14 dias.

As lâminas foram coradas por "Picrosirius red" e a análise das fibras colágenas foi avaliada por digitação de imagens obtidas na linha de sutura, baseados nos princípios de espectrofotometria. Para a quantificação das áreas representativas de colágeno, foram digitalizados 2 campos. Cada campo digitalizado apresentou uma resolução de 640 pontos na horizontal por 480 pontos na vertical e 24 bits de cores (16 milhões de cores). $O$ campo digitalizado correspondeu a uma área de 395 micra de largura por 300 micra de altura na imagem real.

O método imunohistoquímico para marcação do anticorpo foi de conjugação pela enzima peroxidase, localizada por intermédio da 3-3' diaminobenzidina (DAB) e visibilizada no microscópio óptico. $\mathrm{O}$ antígeno macrofágico CD 68 encontrado no citoplasma do macrófago foi detectado pelo anticorpo monoclonal HAM 56. Para que esta reação fosse visibilizada foi utilizado o revelador da reação $\mathrm{DAB}$, que corou os

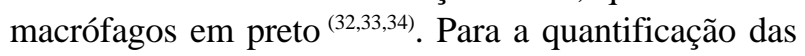
áreas representativas de colágeno e macrófagos, foram digitalizados 2 campos. Todas as imagens digitalizadas foram padronizadas quanto à intensidade de luz do microscópio e a altura do condensador. Para cada imagem quantificada, utilizou-se o mesmo intervalo de cor para separar a área a ser quantificada. Calculou-se então, a área ocupada e a quantidade de luz absorvida pelo colágeno e pelo macrófago em cada um dos campos.

Para a análise dos resultados foram utilizados testes do qui-quadrado, Fisher e de Mann-Whitney (p $\leq 0,05)$. 


\section{Resultados}

TABELA 1 - Porcentagens de fibras colágenas na parede abdominal aos sete e quatorze dias de observação.

\begin{tabular}{ccccc}
\hline & Sutura Contínua & \multicolumn{2}{c}{ Sutura Oito vertical } \\
\hline & $\mathbf{7}$ dias & 14 dias & $\mathbf{7 d i a s}$ & $\mathbf{1 4}$ dias \\
\hline 22,2 & 0,0 & 68,6 & 0,2 \\
& 12,2 & 0,5 & 8,5 & 0,9 \\
& 3,5 & 0,3 & 65,6 & 1,2 \\
23,4 & 1,0 & 94,0 & 0,2 \\
& 38,9 & 111,3 & 0,5 \\
& 6,8 & 0,9 & 92,4 & 0,0 \\
& 57,0 & 1,0 & 41,6 & 0,5 \\
& 2,0 & 0,1 & 40,9 & 0,1 \\
& 40,7 & 0,9 & 32,1 & 0,4 \\
& 6,5 & 0,6 & 47,9 & 0,4 \\
& 9,2 & 1,2 & 31,6 & 0,4 \\
& 7,0 & 0,2 & 45,4 & 0,4 \\
\hline Média & 19,1 & 0,2 & 56,7 & 0,4
\end{tabular}

TABELA 2 - Porcentagens de macrófagos na parede abdominal aos sete e quatorze dias de observação.

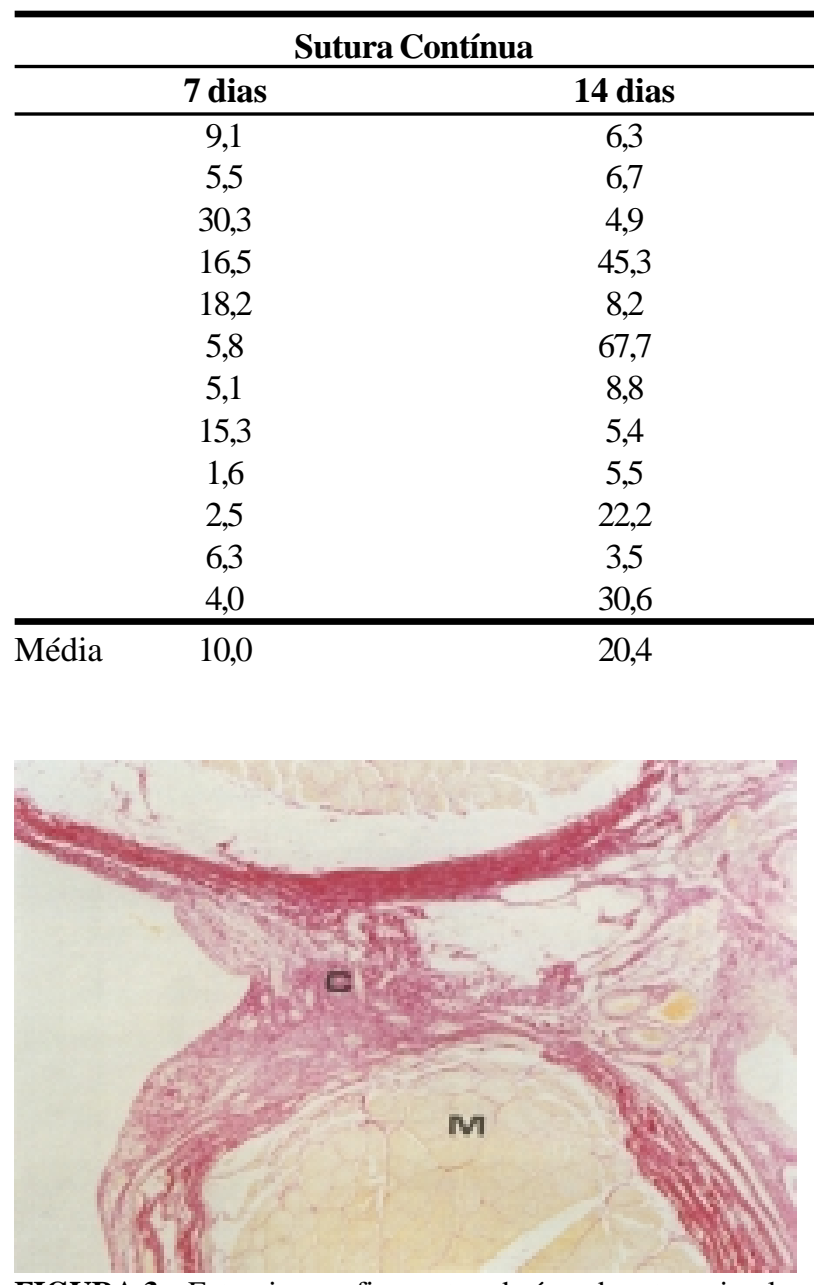

FIGURA 3 - Fotomicrografia mostrando área de sutura simples contínua na parede abdominal de rato após 14 dias, onde o colágeno (C) aparece em vermelho e o tecido muscular (M) em amarelo. Picrosirius 180X.

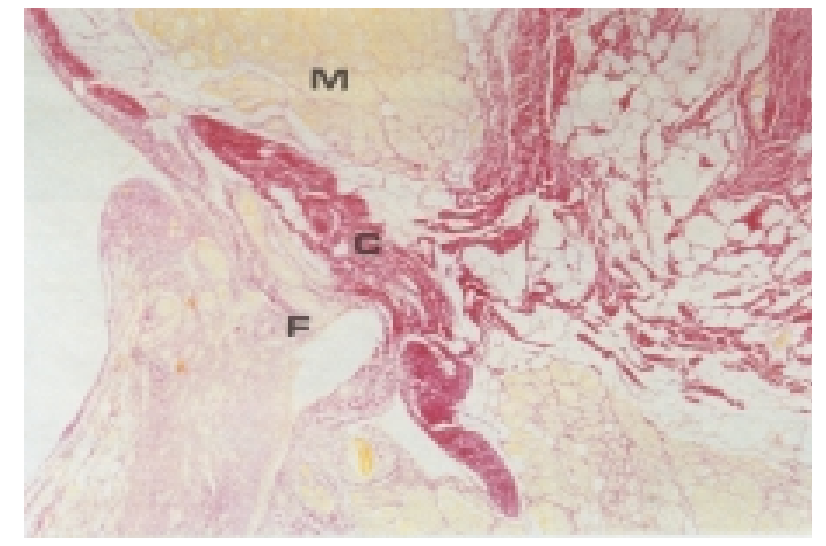

FIGURA 4 - Fotomicrografia mostrando área de sutura contínua em oito vertical na parede abdominal de rato após 7 dias. Notar o tecido muscular (M), o orifício correspondente ao local do fio de sutura $(\mathrm{F})$ e a grande concentração de fibras colágenas (C) coradas em vermelho. Picrocirius red $180 \mathrm{X}$. 


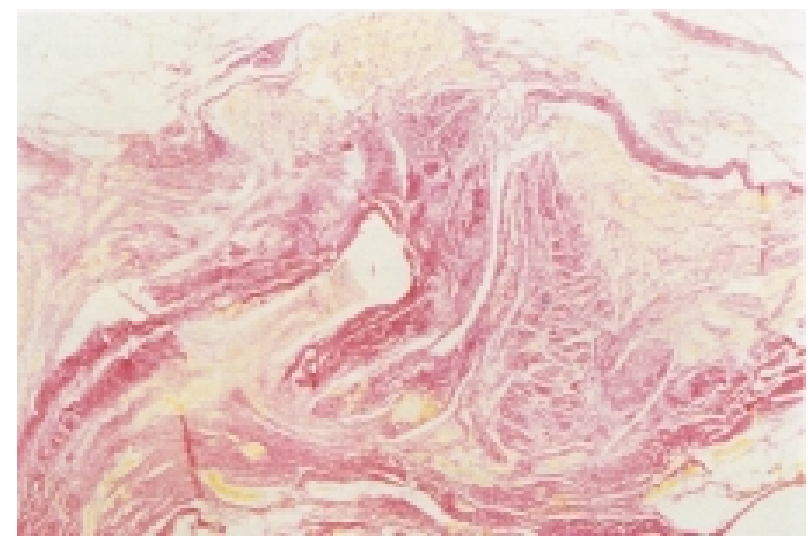

FIGURA 5 - Fotomicrografia mostrando área de sutura contínua em oito vertical na parede abdominal de rato após 14 dias. Picrocirius red $180 \mathrm{X}$.

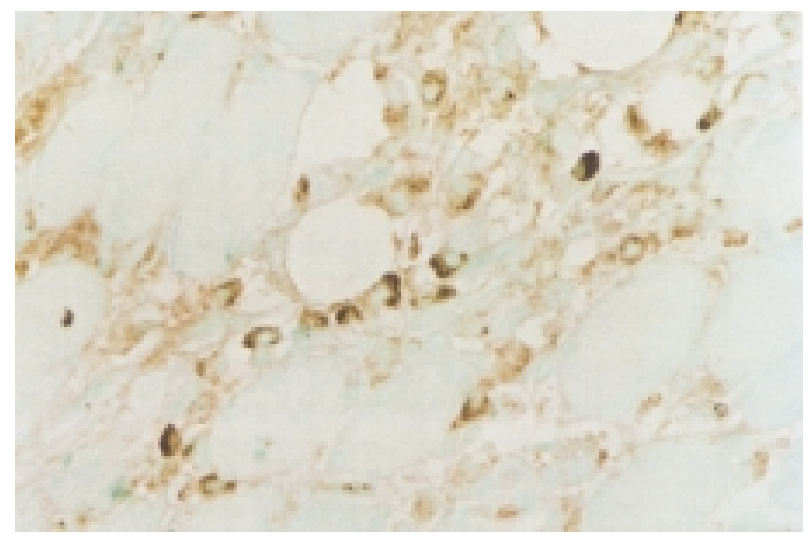

FIGURA 7 - Fotomicrografia mostrando área de sutura contínua em oito vertical na parede abdominal de rato após 7 dias. Observar menor concentração de macrógrafos, em relação ao exemplo anterior, em preto. Imunohistoquímica (HAM 56) 250X.

\section{Discussão}

Apesar do avanço do conhecimento, ainda não se conhecem todos os fenômenos biológicos e químicos que envolvem a cicatrização. Um fator importante e de grande interferência no processo de cicatrização é o material utilizado na confecção da sutura: o fio cirúrgico. A aplicação de fios de sutura interfere nestes fenômenos, daí a busca incessante de material que produza a menor reatividade biológica. Existem evidências de que os fios monofilamentares inabsorvíveis provocam menor reação tecidual e menor grau de contaminação ${ }^{(13,14,15)}$.

Assim, como interessava o estudo comparativo entre duas técnicas de síntese da parede abdominal, foi escolhido o fio de polipropileno monofilamentar, que é considerado como sendo bastante inerte, que causa pouca reação tecidual e, portanto, tendo influência mínima no processo de avaliação da cicatrização.

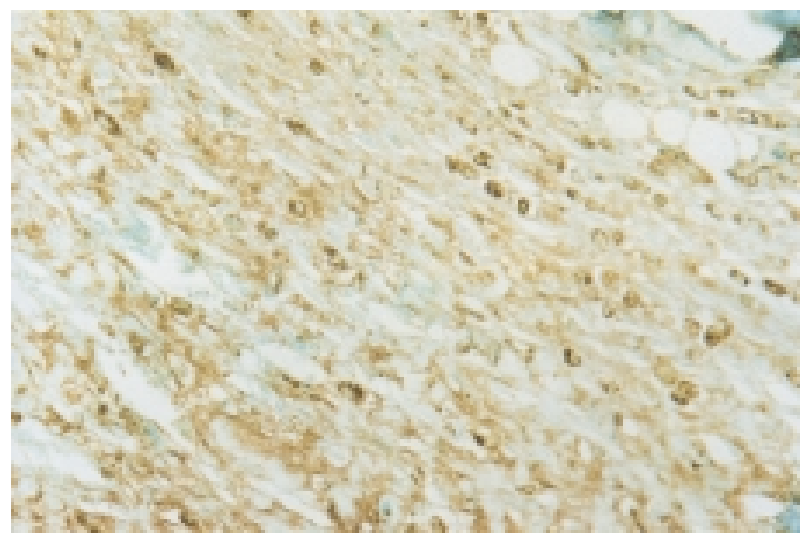

FIGURA 6 - Fotomicrografia mostrando área de sutura contínua na parede abdominal de ratos após 7 dias. Observar grande concentração de macrógrafos, em preto. Imunohistoquímica (HAM 56) 210X.

A seleção da técnica de sutura é uma variável que depende do preparo técnico e experiência do cirurgião. Estudos comparativos entre o fechamento em plano único ("em massa") do conjunto peritônio-músculosaponevrose da parede abdominal, com sutura contínua ou interrompida, demonstram resultados conflitantes, sobre qual é a mais adequada e, conseqüentemente, mais resistente à força de tensão $(1,2,4,5,6,7,8,10)$.

Os proponentes do fechamento interrompido longe-perto/perto-longe acreditam no aumento da resistência da ferida à tensão no interior da laçada da sutura, que mantém as bordas da incisão em aproximação íntima. Os partidários de fechamento "em massa" contínuo teorizam que a força da ferida é devida à distribuição plana de tensão ao longo do comprimento da sutura toda, ao invés de se concentrar individualmente, como nas suturas interrompidas ${ }^{(12)}$.

Meeks et al. ${ }^{(12)}$ trabalhando com ratos, comparando duas suturas contínuas tipo chuleio simples transverso (Figura 1) e em oito-vertical (Figura 2), avaliaram a força tênsil de ruptura das cicatrizes, através de balão intraperitoneal inflável, encontrando valores significantemente maiores para a sutura em oito-vertical aos 7 dias de pós-operatório.

A proposição de Meeks et al. ${ }^{(12)}$ baseou-se em princípios físicos, demonstráveis matematicamente, que justificavam a realização do oito-vertical. A sutura em oito-vertical é análoga a um sistema mecânico de polias distribuindo as forças, que tentam romper a ferida. Por meio da laçada dupla as forças de tensão são distribuídas por um maior número de pontos, ao contrário da laçada única. A sutura contínua aumenta a eficácia, assegurando que a força seja distribuída uniformemente ao longo de todo comprimento da incisão e não se concentrando em pontos específicos da sutura; oferecendo maior repouso à ferida facilita a 
reparação e cicatrização. Este fato motivou a realização da pesquisa procurando fazer uma avaliação do processo de reparação da parede abdominal do rato, com o estudo histológico de quantificação de colágeno e macrófagos na linha de sutura, por meio de computação gráfica ${ }^{(16,17)}$.

O período para avaliação do experimento foi de 7 e 14 dias de pós-operatório mantendo-se como referência o estudo de Dudley ${ }^{(18)}$ onde ficou demonstrado que a cicatriz de incisões suturadas da parede abdominal obtêm coaptação e resistência própria às forças de tensão em períodos progressivos do $7^{\circ}$. ao $14^{\circ}$. dia . Poole $\mathrm{Jr}^{(19)}$ constatou que a força intrínseca numa cicatriz aponeurótica em 14 dias era de $80 \%$ em relação a tecido não incisado, concluindo que os fios não contribuem para a força de tensão após 14 dias.

A cicatrização pode ser avaliada por meio da força tênsil, da tensão de ruptura e da quantificação do colágeno.

O colágeno é o responsável pela resistência e integridade de todos os tecidos, sendo que a força e a integridade do tecido de reparação reside no tipo e quantidade de fibra colágena. O conteúdo de colágeno fornece a base bioquímica para as mudanças da força tênsil e da tensão de ruptura ${ }^{(20)}$.

Encontrou-se porcentagem de fibras colágenas (Tabela 1 e Figuras 3, 4 e 5) significantemente maior, apenas no $7^{\circ}$ dia, na sutura contínua em oito vertical quando comparada à sutura simples contínua. Meeks et al. ${ }^{(12)}$ afirmaram que a sutura contínua em oitovertical apresenta maior força tênsil comparada à sutura simples contínua. Acrescentam ainda, através do estudo histológico, que é maior a porcentagem de fibras colágenas na sutura contínua em oito-vertical.

Quanto aos resultados histológicos, a análise qualitativa, nos parâmetros necrose, fibrose, neovascularização, presença de abscesso, reação de corpo estranho e coaptação das bordas de sutura não mostrou dados significantes (teste exato de Fisher ou o teste do qui-quadrado), nos dois grupos aos 7 ou 14 dias.

O estudo imunohistoquímico, devido à especificidade da técnica utilizada, permitiu a identificação e quantificação dos macrófagos e contribuiu para o estudo da ação destas células na cicatrização da parede abdominal dos animais.

A sequiência de eventos do processo de cicatrização pode ser resumida da seguinte maneira: o ferimento é seguido imediatamente pela coagulação e alteração da vascularidade. A coagulação é mediada por plaquetas e durante a formação do trombo, são liberados fatores plaquetários que aceleram a migração e proliferação da principal célula do processo cicatricial, o fibroblasto (21). Imediatamente segue-se a vasodilatação, aumento da permeabilidade vascular, e a seguir o monócito migra para dentro da ferida. Os monócitos transformam-se em macrófagos ao fagocitarem os detritos e bactérias (22). Simões et al. ${ }^{(23)}$ descreveram, em estudo de ferida na pele do dorso de ratos, abundante presença de macrófagos durante o processo de reparação com a função primordial de fagocitose de células degeneradas, liberação de enzimas hidrolíticas e de substâncias moduladoras da cicatrização.

A porcentagem de macrófagos (Tabela-2 Figuras 6 e 7) mostrou-se significantemente maior (teste de Mann-Whitney) na sutura simples contínua do que na sutura contínua em oito-vertical, aos 7 dias.

A sutura contínua em oito-vertical, apesar de ser uma técnica em dupla volta, não levou a um processo isquêmico maior que o chuleio simples transverso. Ao contrário, a sutura contínua em oito-vertical produziu um menor processo inflamatório tecidual, menor quantidade de macrófagos e maior quantidade de fibras colágenas na linha de sutura, aos 7 dias. Pode-se inferir que a sutura em oito-vertical aos 7 dias, já se apresentou mais organizada, com a presença de macrófagos e formação de colágeno mais precocemente que a sutura simples. Estes resultados sugerem vantagens na realização de sutura contínua em oito-vertical, pois no período crítico de complicações ( $7^{\circ}$ pós-operatório) mostrou menor processo inflamatório e maior porcentagem de fibras colágenas. Sendo o colágeno o responsável pela resistência e integridade dos tecidos, a maior quantificação do colágeno, pode resultar em uma maior força tênsil, sugerindo que a sutura contínua em oito-vertical é mais adequada que a sutura simples contínua.

A proposta da técnica operatória em oito-vertical, baseada em distribuição de forças mecânicas à semelhança de uma polia, mostrou que apresenta vantagens sobre a sutura contínua simples. Outros aspectos precisam ser estudados para uma melhor avaliação dos benefícios no processo de cicatrização e conseqüente diminuição dos riscos de complicações advindas da síntese da parede abdominal.

\section{Conclusão}

No $7^{\circ}$ dia de pós-operatório a parede abdominal suturada em oito vertical apresenta significantemente, maior quantidade de fibras colágenas e menor quantidade de macrófagos do que a suturada por técnica contínua. Aos 14 dias de observação as suturas mostraram-se morfologicamente semelhantes. 


\section{Referências}

1. Tognini JRF, Fagundes DJ, Novo NF et al. Estudo biomecânico e morfológico da cicatrização da parede abdominal sob ação de meloxicam. Acta Cir Bras 2000;15 (3): 45-51.

2. Tognini JRF, Goldenberg S, Simões MJ et al. Efeito do diclofenaco de sódio na cicatrização da parede abdominal de ratos. Acta Cir Bras 1998, 13 (3): 52-9.

3. Tognini JRF, Daniela N, Souza A et al. Efeito da conservação por formas de congelamento na avaliação da força de rotura de cicatrizes da parede abdominal de ratos. Acta Cir Bras 1998;13(4): 39-44

4. Tognini JRF, Goldenberg S. Síntese da parede abdominal: sutura contínua ou com pontos separados? Revisão da literatura. Acta Cir Bras 1998; 13(2): 23-9.

5. Tognini JRF, Goldenberg S, Naresse LE et al. Estudo comparativo entre a sutura contínua e a com pontos separados na parede abdominal de ratos. Acta Cir. Bras 1997; 12(4):23-6.

6. Rucinski J, Margolis M, Panagopoulos G, Wise L. Closure of the abdominal midline fascia: meta-analysis delineates the optimal technique. Am Surg 2001; 67(5):421-6.

7. Carlson MA .New developments in abdominal wall closure. Chirurg 2000; 71(7):743-53.

8. Hüer J, Klinge U, Schachtrupp A, Tüns C, Schumpelick V. Influence of suture technique on laparotomy wound healing: an experimental study in the rat. Langenbecks Arch Surg 2001; $386(3): 218-23$.

9. Olejník J, Stránava I, Hladík M. Causes of rupture in laparotomy incisions. Rozhl Chir 1999; 78(5):248-51.

10. Niggebrugge AH, Trimbos JB, Hermans J, Steup WH, Van De Velde CJ. Influence of abdominal-wound closure technique on complications after surgery: a randomised study. Lancet1999; 353(9164):1563-7.
11. Jones TE, Newell ET, Brubaker RE. The use of alloy steel wire in the closure of abdominal wounds. Surg Gynecol Obstet 1941;72:1056-9.

12. Meeks GR, Nelson KC, Byars RW. Wound strength in abdominal incisions: a comparison of two continuous mass closure techniques in rats. Am J Obstet Gynecol 1995;1: 1676-83.

13. Chaib AS, Ling WS, Vasconcelos E.-Avaliação experimental dos fios na sutura em um só plano. Rev Paul Med 1972;80:217-26.

14. Everett WG.Sutures, incisions and anastomosis. Ann Ver Surg Engl 1975;55:31-8.

15. Paterson-Brown S, Cheslyn-Curtis S, Biglin J, Dye J, Easmon CSF, Dudley, HAF. Suture materials in contaminated wounds: a detailed comparison of a new suture with those currenthy in use. Br J Surg 1987;74:734-5.

16. Schalkoff RJ. Digital image processing and computer vision. Ed Willy 1989.

17. Mascarenhas NDA. Introdução ao processamento digital de imagens. Jornada Epusp \Imagens em computação visual. São Paulo 1990;387-420.

18. Dudley HAF. Layered and mass closure of the abdominal wall: a theoretical and experimental analysis. Br J Surg 1970;57:664- 7.

19. Poole Jr GV. Mechanical factors in abdominal wound closure: the prevention of fascial dehiscence. Surgery 1985;97:631-9.

20. Kleiman I, Simões MJ, Goldenberg S. Aspectos atuais do processo de reparação tecidual. Acta Cir Bras 1987;2:19-21.

21. Laffont J. Dynanique et morphologic d'une plaie cutanne de deuxiéme intention chez la truie: étude des 15 premiers jours. Thése-Doctorat, Universite Paul Sabatier, France, 1984.

22. Wald SM, Arend WP, Ross R. The effect of complement depletion on wound healing. Am J Pathol 1974;74:73-80.

23. Simões MJ, Cabral ACV, Boyacin B, Kulay Jr D, Sasso WS. Aspectos estruturais do processo de reparação da pele de ratos albinos. Rev Paul Med 1996;104:132-5.

Loureiro VM, Fagundes DJ, Taha MO. Abdominal wall syntheses: comparison between two types of continuous suture. Acta Cir Bras [serial online] 2003 May-Jun;18(3). Available from URL: http:/ /www.scielo.br/acb.

\begin{abstract}
Purpose: To establish morphologic relationship between the continuous "simple mass" suture and the continuous far-near, near-far mass suture of longitudinal midline abdominal incision. Methods: A total of 48 male Wistar rats underwent longitudinal standard laparotomy with equal distribution to one of two groups: GI- continuous "simple mass" suture, GII-continuous far-near, near-far suture, both with polypropylene. On postoperative day $7_{\text {th }}$ or $14_{\text {th }}, 12$ animals of each group were submitted to euthanasia and anterior abdominal wall was removed (without skin) for histologic and immune- histochemistry analysis. The samples of the abdominal wall were stained by hematoxylin-eosin in order to performed a qualitative healing tissue reaction. Others samples were stained by Picrosirius red F3BA in order to performed a quantitative analysis of macrophages and collagen. Statistical analysis was done by use the chi-square test, Fisher exact test and Mann-Whitney variance test ( $\mathrm{p} £$ 0,05). Results: The findings of the macrophages cells and the collagen evaluation were statistical significantly on day $7^{\text {th }}$. Conclusion: The continuous far-near, near-far technique improved the abdominal wall healing on day $7^{\text {th }}$. On day $14^{\text {th }}$ the findings were the same.
\end{abstract}

KEY WORDS - Abdomen. Rats, Wistar. Suture techniques. Abdominal wall.

Correspondência:

Murched Omar Taha

Rua Borges Lagoa, 1231/Cj. 62

04038-004 São Paulo - SP

Tel: (11)5084-0100 - taha@uol.com.br
Conflito de interesse: nenhum Fonte de financiamento: nenhuma

Data do recebimento: 20/02/2003

Data da revisão: 04/03/2003

Data da aprovação: 12/03/2003 